Corresponding Author: K. T. Adesina; email: teminikike@yahoo.com

Received 6 December 2017 Accepted 10 March 2018 Published 14 March 2018

Production and Hosting by Knowledge $\mathrm{E}$

(c) Kikelomo T. Adesina et al. This article is distributed under the terms of the Creative Commons Attribution License, which permits unrestricted use and redistribution provided that the original author and source are credited.

Editor-in-Chief:

Prof. Mohammad A. M. Ibnouf

\section{Research Article}

\section{Knowledge, Practice and Acceptability of HPV Vaccine by Mothers of Adolescent Girls in Ilorin, Nigeria}

\section{Kikelomo T. Adesina ${ }^{1}$ (D), Aishat Saka², Salamat A. Isiaka-Lawal33, Omotayo 0.

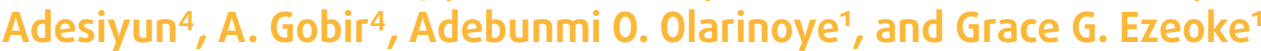

${ }^{1}$ Senior Lecturer/Honorary Consultant, Department of Obstetrics and Gynaecology, University of Ilorin/University of llorin Teaching Hospital, Nigeria

${ }^{2}$ Senior Lecturer/Honorary Consultant, Department of Paediatrics and Child Health, University of Ilorin/University of IlorinTeaching Hospital, Nigeria

${ }^{3}$ Consultant Obstetrician and Gynaecologist, Department of Obstetrics and Gynaecology, Sobi Specialist Hospital, llorin, Nigeria

${ }^{4}$ Associate Professor/Honorary Consultant, Department of Paediatrics and Child Health, University of Ilorin/University of IlorinTeaching Hospital, Nigeria

\section{Abstract}

Background: Human Papilloma Virus (HPV) is a sexually transmitted cause of carcinoma of the cervix. An important determinant of the success of a primary preventive strategy like HPV vaccination is the knowledge and willingness of parents to vaccinate adolescents before sexual debut.

Materials and methods of study: A cross sectional descriptive survey of mothers of girls in 8 secondary schools in Ilorin was carried out from February to April 2015. Schools were selected using multi staged sampling. Descriptive and inferential statistics were performed with Chi Square and ANOVA.

Results: There were 470 questionnaires returned for analysis out of 600 , giving a response rate of $78.3 \%$. One hundred and sixty-one (34.3\%) knew HPV to be sexually transmitted infection and $40.4 \%$ knew it was the cause of cervical cancer. While $35.1 \%$ were aware of HPV vaccine, only $1.9 \%$ had ever vaccinated their children. Less than half $(44.9 \%)$ were willing to vaccinate their children. Women with good knowledge of HPV and cervical cancer were more willing to vaccinate their children than women with poor knowledge $(P<0.001)$.

Conclusion: There is poor knowledge of HPV and practice of vaccination among mothers in llorin. Willingness of mothers to vaccinate their daughters is suboptimal. Mother's knowledge is an important determinant of HPV vaccination of adolescents.

Keywords: Human Papilloma Virus, HPV vaccine, prepubertal HPV vaccination, Adolescent girls' vaccine, llorin

\title{
S OPEN ACCESS
}




\section{INTRODUCTION}

The global burden of cervical cancer has reached epidemic rates and as such calls for primary prevention especially in areas of high prevalence. Carcinoma of the cervix is the leading gynecological cancer in our environment and the second commonest female cancer worldwide [1]. It is responsible for over 8,000 deaths annually from advanced disease and late presentation $[2,3]$.

Studies have shown that many of our women are aware of the disease and there is an increasing level of awareness about its prevention through screening for its premalignant state. A survey conducted among women seeking gynecological and family planning services in University of Ilorin Teaching Hospital (UITH), showed that $78.2 \%$ of the respondents were aware of cervical cancer, half of them knew it can be prevented but over two-thirds had no idea of the cause [4]. Similarly, there is a higher prevalence of Human Papilloma Virus( HPV) infection in women with cervical lesions than those not affected [5].

The discovery of the etiological role of the sexually transmitted HPV in carcinoma of the cervix has re- directed the preventive strategies towards vaccination against the virus before exposure to the infection [6]. The vaccination of pre-pubertal girls and women of $12-26$ years is the current primary preventive strategy in lime light; this has by no means de-emphasized screening for the pre malignant state of the disease. Unfortunately, knowledge and practices concerning the HPV infection and prevention; its effect and role in the primary prevention of cervical cancer are very low and not encouraging $[4,7]$. Estimates suggest that introducing HPV vaccination at 12 years of age alongside the current U.S. screening program for cervical cancer could reduce lifetime cervical cancer incidence by up to $94 \%$ [8].

The safety and efficacy of prophylactic HPV vaccines against types 16, 18, 11,6 and even 16/18 related $\mathrm{CIN}_{2} / 3$ and adenocarcinoma in situ are well established [911]. Worldwide, the available preparations of the prophylactic vaccines are expensive and there is need to educate the populace on the importance and justify the long term cost effectiveness.

In the United Kingdom, United States of America, Netherlands, some parts of Australia and New Zealand, HPV vaccine has been included in the school vaccination program for girls. In the developed world, studies have shown the varying attitudes of parents and guardians towards HPV vaccination of their children and wards; this is not unrelated to the general pervasive lack of knowledge of HPV as a Sexually Transmitted Infection (STI) and a cause of cervical cancer [12]. 
An important determinant of uptake of this primary prevention strategy is the attitude and willingness of parents of these girls to the vaccine. Their knowledge remains an important pivotal to acceptance of the vaccine.

In a developing society like ours most vaccination programmes are highly subsidized or provided freely by donor agencies, in order to have a wide coverage. HPV vaccine has not yet been subsidized. The socioeconomic capacity of parents may also determine acceptability [5] as documented by Dahlstrom et al in a population based survey in Sweden [12]. Since the vaccine is currently available for girls below 18 years, parents have to give consent for the child to be vaccinated. Parental knowledge and attitude would influence parental willingness which will indirectly translate to the uptake of the vaccine.

Baseline data are therefore necessary for national and local awareness and campaign programmes to ensure the acceptability and uptake of the vaccine.

This study was to determine the knowledge of parents about HPV infection, their awareness about HPV vaccine and willingness to vaccinate their daughters. Hopefully, it would be an important foundation for the incorporation of HPV vaccine into the National Immunization Programme in Nigeria.

\section{MATERIALS AND METHODS}

This was a cross sectional descriptive survey involving mothers of selected secondary school girls. It was carried out in llorin from February to April 2015. Ilorin is the capital of Kwara State in Nigeria. It is located in the North central geopolitical zone of the country. It has three local government areas and the settlement is semi-urban. The main ethnic groups in the city are Yorubas, Fulanis and Hausas.

The sample size was determined by Fischer's formula using a prevalence rate of $14 \%$ according to Nnondu et $\mathrm{al}^{7}{ }^{2} 2 \%$ of the calculated sample size was added to cater for incomplete and non-responses. The minimum sample size calculated was 250 participants (parent/daughter pair).

The list of the registered secondary schools in Ilorin was obtained from the State Ministry of Education after obtaining permission from the Ministry and ethical approval from the Ethical Review Board of the University of Ilorin Teaching Hospital, Ilorin. A multi stage sampling method was utilized to select secondary schools from the list of schools which included both public and private secondary schools.

At the selected schools, girls between 10 and 15 years were randomly selected from Junior Secondary Classes of these schools until the calculated sample size was reached. 
A minimum of 40 girls were randomly sampled from each school. Their parents were invited to participate voluntarily in the study during open / visiting days for the boarding students while invitations were sent through the day students to their parents. The invitation included an information sheet, consent form and the questionnaire. A week after the distribution, the researchers returned to collect the completed questionnaires from the girls through their class teachers.

The instrument for this survey was a close ended (multiple choice) self administered questionnaire designed to determine the knowledge, attitude and willingness of participants to HPV vaccination. The study respondents were assured of anonymity and confidentiality and first part of the questionnaire provided socio-demographic information of the mothers. The second part assessed their knowledge of HPV infections, vaccines and their willingness to accept HPV vaccine for daughters. There was no health education on the subject for the participants before completion of the questionnaire. Mothers completed the survey items for this study only once, even if they had more than 1 child enrolled in the schools. The questionnaire was pre-tested in a similar population for validity and reliability using $20 \%$ of the calculated size.

Data analysis was done using SPSS version 20 with both descriptive and inferential Statistics. In particular, Chi-square statistics were used to estimate the degree of correlation between the variables and nature of the independent variables in this study. $P$ values less than 0.05 were considered significant.

\section{RESULTS}

\subsection{Socio-demographic characteristics of respondents}

Six hundred questionnaires were distributed to mothers of female students from selected secondary schools however, 470 questionnaires were returned for analysis, giving a response rate of $78.3 \%$.

Majority of the respondents (61.9\%) were between 31 and 50 years, $83.6 \%$ were of Yoruba ethnicity. The parents were either Christians or Muslims and 58.1\% had at least secondary school education. Among the respondents, $70.2 \%$ were employed out of which $171(51.8 \%)$ were civil servants. Among the $91.9 \%$ of the respondents whose social class could be determined, $22.8 \%$ (107) belonged to the upper social class. (Table 1). 


\subsection{Knowledge of HPV infection}

One hundred and sixty-one (34.3\%) of the respondents knew that HPV can be sexually transmitted and 34.5 percent knew that it could be prevented by use of condoms. Sexual abstinence and having one sexual partner were suggested as preventive measures for HPV infection by $27.9 \%$ and $37.7 \%$ of the respondents, respectively. Even though $40.4 \%$ knew that HPV can cause cervical cancer, a higher percentage of $47.7 \%$ did not know that HPV can cause cervical cancer (Table 2).

\subsection{Knowledge of HPV vaccine}

Out of the study participants, 35.1\% were aware of HPV vaccine and majority (58.7\%) has not heard of the vaccine. The hospital/medical personnel were the sources of information in $\mathbf{2 8 . 1} \%$ while other sources such as mass media, health talks, journal/magazines accounted for approximately $15-21 \%$ (Table 3 ).

HPV vaccine was known to prevent HPV infection by only $29.1 \%$ of the respondents, $25.5 \%$ knew it prevented cervical cancer while only $9.6 \%$ knew it could prevent genital warts (Table 3 ).

Among the respondents, 33.8\% knew it was available in Nigeria. As many as $83 \%$ of the respondents gave no response about the available types of HPV vaccine but $15.3 \%$ had no knowledge whatsoever about the types of vaccine.

Among the study participants, only 1\% knew that Cervarix and/or Gardasil are HPV vaccines, while two mothers wrongly considered the routine immunization schedule as the vaccine.

Some respondents, $32.3 \%$ answered that all girls should be vaccinated while $6.4 \%$ thought otherwise; $11.3 \%$ responded that it should be given to only sexually active girls and $1.1 \%$ opined that boys should also be vaccinated.

\section{PRACTICE AND WILLINGNESS TO ACCEPT HPV IMMUNIZA- TION}

Majority $(91.9 \%)$ of the parents responded that their girls have not been immunized with HPV vaccine. Of the 9 respondents (1.9\%) whose children have been immunized, immunization was given between $11 a n d 20$ years in $77.8 \%$ of them. Among the $7 \%$ of women that knew HPV immunized persons, only few (2.3\%) reported abdominal cramps, body pains, lethargy as side effects of the vaccine in them (Table 4 ). 
In this survey, $44.9 \%$ of the women were willing to vaccinate their children with HPV vaccine even when only $13 \%$ had enough information to decide on acceptance of the vaccine. Furthermore, $37.9 \%$ would like further consultation with a doctor or any health care provider before accepting the vaccine. In terms of cost, $22.3 \%$ would accept the vaccine only if free, 33 . \% of the respondents will do so even if vaccine is not free. One hundred and fifty two $(32.3 \%)$ of the respondents are willing to give the vaccines to all girls while $11.3 \%$ of them would be willing to give the vaccine to sexually active girls only (Table 5 ).

Respondents that were willing to vaccinate their girls had a mean score of 5.00 \pm 3.32 about the knowledge of HPV while those not willing had a score of $4.92 \pm 2.93$. Similarly, the knowledge score of HPV Vaccination was higher among half of those willing to vaccinate and it was significant statistically ( $\mathrm{P}$ 0.0001) Tables 687.

\section{DISCUSSION}

The age distribution of the study population ranged from the highly reproductive age to peri-menopausal age; most respondents were between 31 and 50 years. Their demographic characteristics showed a variation in terms of age, education, marital status, social class among others. Mothers in the upper social class were the least when compared with those in the lower and middle classes. This is most likely a representation of the semi-urban pattern of the population of Ilorin, Nigeria. There was poor knowledge of HPV infection and practice of vaccination among mothers. The willingness to accept HPV vaccine was low and there was a significant statistical relationship between acceptability of HPV vaccine and knowledge of HPV infection, vaccination and cervical cancer.

\section{KNOWLEDGE OF HPV INFECTION AND VACCINE}

The mothers of girls in this study demonstrated poor knowledge of Human papillomavirus infection and vaccine as $34.5 \%$ of the respondents had a score of 5 or more (correct knowledge). This is similar to findings from some developing countries [13-17]. For example, in Ghana and Cameroon, parents of adolescents had poor knowledge of HPV and its vaccination $[16,17]$. Our findings indicate that women in llorin are poorly informed about HPV and cervical cancer, this is similar to those of other developing countries. 
This is however, in contrast to findings among Cameroonian adolescents who displayed high level of awareness on HPV, cervical cancer and HPV vaccine [18]. Prior sensitization and health education was found to result in the high level of awareness among the girls when compared with the poor knowledge and awareness among mothers in our study. Also, standard educational script on risk factors and prevention of HPV infection and cervical cancer was given to the women that participated in a similar survey in Zambia and this positively influenced their acceptability of the vaccine [14]. Education on HPV and cervical cancer prevention would increase access to screening and other preventive measures [19]. It was concluded that community education was the effective strategy for acceptability of HPV immunization in the setting.

The practice of HPV vaccination was very low in this study; poor knowledge of the vaccine and the role of the virus in the widely prevalent cervical cancer in the environment is a contributory factor. In addition to the poor knowledge of the etiological role of HPV in carcinoma of cervix, majority knew little to nothing about availability and types of HPV vaccines. This is rather unacceptable, knowing that the vaccine has been licensed for use in the U.S.A, since 2006 [20] and has even become part of some national immunization programs in both developing and developed worlds [10, 11, 14, $15,19,20]$. This probably explains the very low percentage of HPV immunized girls in this study.

The roles HPV vaccines in the prevention of cervical cancers and genital warts are well established. Cervarix is a bivalent HPV vaccine that prevent HPV types 16 and 18 serotypes responsible for $70 \%$ of cervical cancers. The other quadrivalent HPV vaccine is Gardasil. It prevents HPV types 6, 11, 16 and 18. HPV 6 and 11 cause 90\% of genital warts. Gardasil also protects against cancers of the anus, vagina and vulva. WHO recommends that settings like Nigeria where there is high prevalence and mortality from cervical cancer should include HPV vaccines into routine national immunization programmes [21]. The role of governmental policy in the implementation of the vaccine is relevant as some women even reported it wrongly as being part of the current national immunization programme in Nigeria.

More women knew that it can prevent cervical cancer while $9.6 \%$ knew it prevents genital warts. It may be that the awareness on cervical cancer is greater than genital warts in our environment because of its high prevalence and associated mortality and morbidity. However, it may be more important to educate the populace on the role of HPV in other gynecological and anogenital cancers; its mode of spread and transmission which is of more public health importance $[10,20]$. 
In addition, there was significant relationship between practice and knowledge of the vaccine. Obviously, health education programs on the condition are either lacking or the education is not targeted at the population at risk.

The willingness to accept HPV vaccine was low and there was a significant statistical difference between acceptability and knowledge of HPV infection and vaccination, and cervical cancer. Where others reported high acceptability [18-24] 44.9\% of mothers indicated willingness to accept the vaccine despite the poor knowledge. Most likely, differences in methodology, prior health education on risk factors and prevention of HPV and cervical cancer before survey and differing study populations are reasons for differences between vaccine acceptability. Thus, health education programmes on HPV infection as a risk factor for cervical cancer and other important related public health matters should form the core strategy for implementation of HPV vaccine in our society and not just merely making the vaccines available.

Another obvious problem with the acceptance of any vaccine is the cost. Approximately, one third of the women were willing to vaccinate their daughters even if the vaccine is not free while a lower percentage of $22 \%$ would accept it only if free. A related survey among Kenyan women showed that most would prefer making the vaccine much lower cost if not free [13]. In Israel, cost of the vaccine was identified as one of the barriers to acceptability of the vaccine among others [2]. Currently Currently, HPV vaccines (Gardasil and Cervarix) are available in Nigeria but their cost is not within reach for an average Nigerian; it is about the recommended minimum wage of any employee in the country, implying that it is unaffordable by majority.

Although undocumented verbal reports are suggesting that more women are requesting to be immunized, it is costly, not affordable and not within reach of all women especially when compared with other vaccine preventable diseases. Until, HPV vaccine is implemented as a national programme, it may never have wide coverage and may never be available to adolescents at future risk of cervical cancer. This strategy would eliminate cost as a factor that may limit the acceptability and willingness of parents to vaccinate their wards and children.

\section{CONCLUSION}

One third of the respondents had correct knowledge of HPV infection, immunization and its role in prevention of cervical cancer; $44.9 \%$ of the mothers were willing to vaccinate, while $10.6 \%$ were not. $41.3 \%$ did not respond probably because of the poor knowledge of HPV. This study has demonstrated the relationship between knowledge 


\begin{tabular}{|c|c|c|}
\hline VARIABLE & FREQUENCY $(\mathrm{N}=470)$ & PERCENT \\
\hline \multicolumn{3}{|l|}{ Age group (years) } \\
\hline$<20$ & 60 & 12.8 \\
\hline $20-30$ & 20 & $4 \cdot 3$ \\
\hline $31-40$ & 131 & 27.9 \\
\hline $41-50$ & 160 & 34.0 \\
\hline $51-60$ & 28 & 6.0 \\
\hline$>60$ & 71 & 15.1 \\
\hline \multicolumn{3}{|l|}{ Nationality } \\
\hline Nigeria & 430 & 91.5 \\
\hline Cameroon & 1 & 0.2 \\
\hline NR & 39 & 8.3 \\
\hline \multicolumn{3}{|l|}{ Ethnicity } \\
\hline Yoruba & 393 & 83.6 \\
\hline Igbo & 12 & 2.6 \\
\hline Hausa & 5 & 1.1 \\
\hline Fulani & 4 & 0.9 \\
\hline Others & 19 & 4.0 \\
\hline NR & 37 & 8.9 \\
\hline \multicolumn{3}{|l|}{ Religion } \\
\hline Christianity & 209 & 44.5 \\
\hline Islam & 218 & 46.4 \\
\hline NR & 43 & 9.1 \\
\hline \multicolumn{3}{|l|}{ Educational status } \\
\hline$<$ Secondary school & 159 & 33.8 \\
\hline Secondary or equal & 99 & 21.1 \\
\hline$>$ Secondary school & 174 & 37.0 \\
\hline NR & 38 & 8.1 \\
\hline \multicolumn{3}{|l|}{ Employment } \\
\hline Yes & 330 & 70.2 \\
\hline No & 83 & 12.1 \\
\hline NR & 57 & 12.1 \\
\hline \multicolumn{3}{|l|}{ Social class } \\
\hline Lower & 174 & 37.0 \\
\hline Middle & 151 & 32.1 \\
\hline Upper & 107 & 22.8 \\
\hline NR & 38 & 8.1 \\
\hline \multicolumn{3}{|l|}{ Family types } \\
\hline Monogamy & 312 & 66.4 \\
\hline Polygamy & 53 & 11.3 \\
\hline Single mothers & 105 & 22.3 \\
\hline \multicolumn{3}{|c|}{ Number of children of respondents } \\
\hline 1 & 15 & 3.2 \\
\hline 2 & 42 & 8.9 \\
\hline$\geq 3$ & 316 & 67.2 \\
\hline
\end{tabular}

TABLE 1: SOCIO-DEMOGRAPHIC PARAMETERS OF RESPONDENTS. 


\begin{tabular}{|c|c|c|}
\hline VARIABLE & FREQUENCY $(\mathrm{N}=470)$ & PERCENT \\
\hline \multicolumn{3}{|c|}{ HPV is sexually transmitted } \\
\hline Yes & 161 & 34.3 \\
\hline No & 66 & 14.0 \\
\hline I don't know & 186 & 39.6 \\
\hline NR & 57 & 12.1 \\
\hline \multicolumn{3}{|c|}{ HPV can be prevented by use of condom } \\
\hline Yes & 162 & 34.5 \\
\hline No & 77 & 16.4 \\
\hline I don't know & 169 & 36.0 \\
\hline NR & 62 & 13.2 \\
\hline \multicolumn{3}{|c|}{$\begin{array}{l}\text { HPV can be prevented by having only one } \\
\text { sexual partner }\end{array}$} \\
\hline Yes & 177 & 37.7 \\
\hline No & 58 & 12.3 \\
\hline I don't know & 169 & 36.0 \\
\hline NR & 66 & 14.0 \\
\hline \multicolumn{3}{|c|}{ HPV can be prevented by abstinence from sex } \\
\hline Yes & 131 & 27.9 \\
\hline No & 72 & $15 \cdot 3$ \\
\hline \multicolumn{3}{|c|}{ Cervical cancer is caused by HPV } \\
\hline Yes & 190 & 40.4 \\
\hline No & 30 & 6.4 \\
\hline I don't know & 224 & 47.7 \\
\hline NR & 26 & 5.5 \\
\hline
\end{tabular}

TABLE 2: RESPONDENTS' KNOWLEDGE OF HPV.

of HPV, willingness and acceptability of HPV vaccines in a semi-urban population in Nigeria, a developing country with high prevalence and mortality from cervical cancer. There is poor knowledge of HPV and its vaccines among mothers in llorin; and they are important determinants of acceptability/ willingness of parents to vaccinate their pre-pubertal girls.

A core preventive strategy is the implementation of the vaccine into National Immunization program after adequate and widespread community education. Addressing 


\begin{tabular}{|c|c|c|}
\hline VARIABLE & FREQUENCY $(\mathrm{N}=470)$ & PERCENT \\
\hline \multicolumn{3}{|l|}{ Have you heard of HPV vaccine? } \\
\hline Yes & 165 & 35.1 \\
\hline No & 276 & 58.7 \\
\hline NR & 29 & 6.2 \\
\hline \multicolumn{3}{|l|}{ Sources of information* } \\
\hline Mass media & 61 & 21.4 \\
\hline Hospital/medical personnel & 80 & 28.1 \\
\hline Newspaper/journals/magazines & 43 & 15.1 \\
\hline Health talk & 60 & 21.1 \\
\hline Peer group/parents & 11 & 3.9 \\
\hline \multicolumn{3}{|l|}{ Others } \\
\hline Internet & 18 & 6.3 \\
\hline Relativ es & 2 & 0.7 \\
\hline Social media & 10 & 3.5 \\
\hline \multicolumn{3}{|l|}{ Prevents HPV infection } \\
\hline Yes & 137 & 29.1 \\
\hline No & 60 & 12.8 \\
\hline I don't know & 261 & 55.5 \\
\hline \multicolumn{3}{|l|}{ Prevents cervical cancer } \\
\hline Yes & 120 & 25.5 \\
\hline No & 84 & 17.9 \\
\hline I don't know & 256 & 54.5 \\
\hline NR & 10 & 2.1 \\
\hline \multicolumn{3}{|l|}{ Prevents genital warts } \\
\hline Yes & 45 & 9.6 \\
\hline No & 88 & 18.7 \\
\hline I don't know & 261 & 55.5 \\
\hline NR & 76 & 16.2 \\
\hline \multicolumn{3}{|l|}{ Is HPV available in Nigeria? } \\
\hline Yes & 159 & 33.8 \\
\hline No & 69 & 14.7 \\
\hline I don't know & 151 & 32.1 \\
\hline NR & 91 & 19.4 \\
\hline \multicolumn{3}{|l|}{ What type of HPV do you know? } \\
\hline None & 72 & $15 \cdot 3$ \\
\hline Abnormal Pap's & 1 & 0.2 \\
\hline Gardasil\&cervarix & 3 & 0.6 \\
\hline Cervarix & 2 & 0.4 \\
\hline Dpt, Bsg, Oral polio & 1 & 0.2 \\
\hline Mycotine & 1 & 0.2 \\
\hline NR & 390 & 83.0 \\
\hline
\end{tabular}

TABLE 3: RESPONDENTS' KNOWLEDGE OF HPV VACCINE. 


\begin{tabular}{|c|c|c|}
\hline VARIABLE & $\begin{array}{l}\text { FREQUENCY } \\
(\mathrm{N}=470)\end{array}$ & PERCENT \\
\hline \multicolumn{3}{|l|}{$\begin{array}{l}\text { Have you immunized your daughter with HPV } \\
\text { vaccine? }\end{array}$} \\
\hline Yes & 9 & 1.9 \\
\hline No & 432 & 91.9 \\
\hline NR & 29 & 6.2 \\
\hline \multicolumn{3}{|l|}{ If yes, at what age? $(n=9)$} \\
\hline $11-20 y г s$ & 7 & 77.8 \\
\hline$>20 y$ гs & 2 & 22.2 \\
\hline \multicolumn{3}{|l|}{$\begin{array}{l}\text { Is there anyone who had HPV vaccine that you } \\
\text { know? }\end{array}$} \\
\hline Yes & 33 & 7.0 \\
\hline No & 315 & 67.0 \\
\hline I don't know & 98 & 20.9 \\
\hline $\begin{array}{l}\text { NR Did the person experience any side effects?(n } \\
=33 \text { ) }\end{array}$ & 24 & 5.1 \\
\hline \multicolumn{3}{|l|}{ Yes } \\
\hline No & 11 & 2.3 \\
\hline I don't know & 12 & 2.6 \\
\hline & 10 & 2.1 \\
\hline
\end{tabular}

TABLE 4: PRACTICE OF HPV VACCINATION AMONG RESPONDENTS.

mothers of adolescent girls would be a desirable target population for implementing other primary preventive measures such as screening for premalignant condition, HPV infection and STIs.

\section{Recommendations}

There is need for intense public campaigns and enlightenment programmes on cervical cancer, HPV and immunization to prevent cervical cancer. Without this, the reduction in cervical cancer mortality may not be realized in the nearest future. 


\begin{tabular}{|c|c|c|}
\hline VARIABLE & FREQUENCY $(\mathrm{N}=470)$ & PERCENT \\
\hline HPV vaccine should be given to all girls & 152 & 32.3 \\
\hline It should be given to sexually active girls only & 53 & 11.3 \\
\hline HPV vaccine should be given to boys & 89 & 1.1 \\
\hline $\begin{array}{l}\text { I have enough information to decide for or } \\
\text { against accepting the vaccine for my child }\end{array}$ & 61 & 13.0 \\
\hline $\begin{array}{l}\text { I need to ask doctor or health worker before } \\
\text { accepting vaccine }\end{array}$ & 178 & 37.9 \\
\hline Are you willing to vaccinate your child? & 211 & 44.9 \\
\hline Willing only if vaccine is free & 105 & 22.3 \\
\hline Willing even if vaccine is not free & 148 & 31.5 \\
\hline
\end{tabular}

TABLE 5: PARENTS' WILLINGNESS TO ACCEPT HPV VACCINE.

\begin{tabular}{l|l|l|l|l}
$\begin{array}{l}\text { Willing to vac- N } \\
\text { cinate child }\end{array}$ & \multicolumn{1}{l}{$\begin{array}{l}\text { Knowledge } \\
\text { score }\end{array}$} & F & p value \\
\hline Yes & 211 & $5.00 \pm 3.32^{a}$ & 65.922 & $<0.001$ \\
No & 50 & $4.92 \pm 2.93^{a}$ & \\
\hline I don't know & 194 & $1.69 \pm 2.71^{b}$ & \\
\hline $\begin{array}{l}\text { F: ANOVA (Analysis of Variance); }{ }^{*} \text { : Statistically significant (i.e. } p \text { value <0.05); Mean } \\
\text { with different alphabets indicate significant difference }\end{array}$
\end{tabular}

TABLE 6: Mean score of respondents' knowledge of HPV and willingness to vaccinate child.

This should be foremost if any HPV immunization programme would be successful in our environment. The cost of the vaccine should be heavily subsidized if not made freely available by the government. The long term benefits are worthwhile.

\begin{tabular}{|c|c|c|c|c|c|c|}
\hline \multirow{2}{*}{$\begin{array}{l}\text { Knowledge } \\
\text { score }\end{array}$} & \multicolumn{4}{|c|}{ Willingness to vaccinate child } & \multirow[b]{2}{*}{$\chi^{2}$} & \multirow[b]{2}{*}{ p value } \\
\hline & Yes & No & I don't know & Total & & \\
\hline & $n(\%)$ & n (\%) & $\mathrm{n}(\%)$ & n (\%) & & \\
\hline $0-4$ & $106(50.2)$ & $24(48.0)$ & $168(86.6)$ & $298(65.5)$ & 69.118 & $<0.001^{*}$ \\
\hline $5-9$ & $78(37.0)$ & $22(44.0)$ & $22(11.3)$ & $122(26.8)$ & & \\
\hline$\geq 10$ & $27(12.8)$ & $4(8.0)$ & $4(2.1)$ & $35(7.7)$ & & \\
\hline Total & $211(100.0)$ & $50(100.0)$ & 194(100.0) & $455(100.0)$ & & \\
\hline
\end{tabular}

TABLE 7: Relationship between willingness to vaccinate child and the respondents' knowledge of HPV and vaccination 


\section{Limitation}

This survey was conducted among mothers who were reached through their daughters and not a community based survey which would have identified mothers directly.

There was no preceding health education on the subject like earlier similar surveys which probably explains the high poor response to many questions. In another instance, this serves as the strength of the study because the poor knowledge was demonstrated distinctively.

\section{DECLARATIONS}

\section{Acknowledgements}

We hereby acknowledge parents of secondary girls who gave consent to participate in the study and the school authorities that ensured due completion of questionnaires. We also acknowledge the support of Prof.T.M Akande in terms of positive critique of the manuscript.

\section{Ethical Approval}

Ethical approval for this study was obtained from Ethical Review Committee of the University of Ilorin Teaching Hospital, Ilorin as well as permission from the Ministry of Education, Kwara State.

\section{Competing Interests}

Authors hereby declaring no competing or conflict of interests.

\section{Availability of data and material}

Data and instruments for this study are available and kept confidential by authors.

\section{Funding}

This work was funded by all authors. 


\section{List of Abbreviations}

HPV Human Papilloma Virus

U.I.T.H University of llorin Teaching Hospital

U.S.A United States of America

CIN Cervical Intraepithelial Neoplasia

STI Sexually Transmitted Infection

SPSS Statistical Package for Social Sciences

WHO World Health Organization

\section{References}

[1] Parkin DM, Bray F. The burden of HPV- related cancers. Vaccine 2006;24:11-25.

[2] WHO/ICO. Information on HPV and Cervical Cancer (HPV Information Centre). Summary report on HPV and Cervical Cancer statistics in Nigeria. 2007 [cited 2013 Feb 12]. Available from:www.who.int/hpvcentre.

[3] Kolawole AO. Cervical Cancer Prevention in Nigeria: Issues Arising. Internet Journal of Gynecology and Obstetrics. 2012 Jan[cited Feb 11];16(1). DOI: 10.5580/2b20.Available from at: http://www.ispub.com/journal/the-internetjournal-of-genomics-and-proteomics.

[4] Adesina K, Saidu R, Aboyeji A, Fawole A, Olarinoye A, Ibrahim K. Factors contributing to low cervical cancer screening in a population at risk. Nig J Health Sci.2010;10:2125.

[5] Ault KA. Effect of prophylactic human papillomavirus L1 virus-like particle vaccine on risk of cervical intraepithelial neoplasia grade 2,grade 3 , and adenocarcinoma in situ: a combined analysis of four randomised clinical trials. Lancet 2007;369:18611868.

[6] Nnodu O, Erinosho L, Jamda M, Olaniyi O, Adelaiye R,Lawson L et al. Knowledge and Attitudes towards Cervical Cancer and Human Papillomavirus: A Nigerian Pilot Study. African Journal of Reproductive Health 2010; 14:95-108.

[7] Goldie S), Kohli M, Grima D, Weinstein MC, Wright TC, Xavier Bosch F ,Franco E . Projected clinical benefits and cost-effectiveness of a human papillomavirus $16 / 18$ vaccine. J Natl Cancer Inst 2004;96:604-15.

[8] Moraros J , Bird Y, Barney D.D ,King S.C ,Banegas M, Suarez-Toriello E. A Pilot Study: HPV Infection Knowledge \& HPV Vaccine Acceptance among Women Residing in 
Ciudad Juárez, México. Californian Journal of Health Promotion 2006; 4:177-186.

[9] Garland SM, Hernandez-Avila M, Wheeler CM, Perez G, Harper DM, Leodolter S, et al. Quadrivalent vaccine against human papillomavirus to prevent anogenital diseases. N Engl J Med 2007;356:1928-1943.

[10] D. Paavonen J, Jenkins D, Bosch FX, Naud P, Salmeron J, Wheeler CM, et al. Efficacy of a prophylactic adjuvanted bivalent L1virus-like-particle vaccine against infection with human papillomavirus types 16 and 18 in young women: an interim analysis of a phase III double-blind, randomised controlled trial. Lancet 2007;369:2161-2170.

[11] Thomas JO, Hererro R, Omigbodun AA, Ojemakinde K, Ajayi IO, Fawole A et al. Prevalence of Human Papilloma Virus Infection in women in Ibadan,Nigeria: a population-based study. $\mathrm{Br}$ J Cancer 2004;90:638-645.

[12] Bosch FX, Lorincz A, Munoz N, Meijer CJ, Shah KV. The causal relation between human papillomavirus and cervical cancer. J Clin Pathol. 2002;55: 244-265.

[13] Becker-Dreps S, Otieno WA, Brewer NT, Agot K, Smith JS.HPV vaccine acceptability among Kenyan women. Vaccine2010;28: 4864-4867.

[14] Liu FW, Vwalika B, Hacker MR, Allen S, Awtrey CS. Cervical Cancer and HPV Vaccination: Knowledge and Attitudes of Adult Women in Lusaka, Zambia. Journal of Vaccines \& Vaccination 2012 doi: 10.4172/2157-7560.1000138

[15] Francis SA, Nelson J, Liverpool J, Soogun S, Mofammere N, Thorpe RJ. Examining attitudes and knowledge about HPV and cervical cancer risk among female clinic attendees in Johannesburg, South Africa. Vaccine 2010;28: 8026-8032

[16] Coleman MA, Levison J, Sangi-Haghpeykar H . HPV vaccine acceptability in Ghana, West Africa. Vaccine.2011; 29: 3945-3950.

[17] Wamai RG, Ayissi CA, Oduwo GO, Perlman S, Welty E, Manga S et al. Assessing the effectiveness of a community-based sensitization strategy in creating awareness about HPV, cervical cancer and HPV vaccine among parents in North West Cameroon. Journal of community health.2012; 37: 917-926.

[18] Ayissi CA, Wamai RG, Oduwo GO, Perlman S, Welty E, Welty T et al. Awareness, Acceptability and Uptake of Human Papilloma Virus Vaccine among Cameroonian School-Attending Female Adolescents. Journal of community health2012; 37: 11271135. doi: 10.1007/s10900-012-9554-z

[19] Perlman S, Wamai RG, Bain PA, Welty T, Welty E, Ogembo JG. Knowledge and of HPV vaccine and acceptability to vaccinate in sub-Saharan Africa: a systematic review. PLoS ONE2014; 9: e90912. doi:10.1371/journal.pone.0090912.

[20] Markowitz LE, Dunne EF, Saraiya M, Lawson HW, Chesson H, Unger ER. Centers for Disease Control and Prevention (CDC); Advisory Committee on munization 
Practices (ACIP) Quadrivalent Human Papillomavirus Vaccine: Recommendations of the Advisory Committee on Immunization Practices (ACIP) MMWR Recomm Rep.2007;56(RR-2):1-24.

[21] Fisher WA, Laniado $H$, Shoval $H$, Hakim $M$, Bornstein J. Barriers to human papillomavirus vaccine acceptability in Israel. Vaccine 2013; 31: 153-157. 